\title{
An efficient regenelation system via somatic embryogenesis in olive
}

\section{Sergio Cerezo • José Á. Mercado* • Fernando Pliego-Alfaro}

Instituto de Hortofruticultura Subtropical y Mediterránea "La Mayora”, Universidad de Málaga-Consejo Superior de Investigaciones Científicas (IHSM-UMA-CSIC), Departamento de Biología Vegetal, Universidad de Málaga, 29071, Málaga, Spain

\section{Corresponding author:}

José A. Mercado

Dep. Biología Vegetal

Universidad de Málaga

29071, Málaga

Spain

e-mail: mercado@uma.es

\begin{abstract}
Olive is one of the most important oil crops in the Mediterranean area. The biotechnological improvement of this species is hampered by the recalcitrant nature of olive tissue regeneration in vitro. In this investigation, we have developed an efficient regeneration system for juvenile olive explants via somatic embryogenesis. Embryogenic cultures were obtained at a rate of $25 \%$ by culturing isolated radicles from mature seeds in an OMc medium containing $2.5 \mu \mathrm{M} 2 \mathrm{iP}$ and $25 \mu \mathrm{M}$ IBA over three weeks and later transferring to the same medium without $2 \mathrm{iP}$ and with a lower IBA concentration. Two different basal formulations, OMc and ECO (1/4 OM macroelements, 1/4 MS microelements and 1/2 OM vitamins supplemented with 550 $\mathrm{mg} \mathrm{l}^{-1}$ glutamine), were tested for embryogenic callus proliferation and maturation. The growth rate of embryogenic calli was similar in both media. However, the regeneration of mature embryos, achieved by culturing embryogenic masses in the same medium without hormones and supplemented with activated charcoal $1 \mathrm{~g} \mathrm{l}^{-1}$, was significantly higher when embryos were cultured in the ECO mineral formulation. Pre-culturing embryogenic masses in liquid medium for up to 4 weeks did not affect subsequent callus proliferation in solid medium. The maturation rate of small globular somatic
\end{abstract}


embryos, 1-3 mm size, obtained after filtering liquid cultures through a $3 \times 3 \mathrm{~mm}$ mesh, was also similar to control embryos cultured in solid medium. To improve the maturation and germination rates, the effect of culturing globular somatic embryos on semi-permeable cellulose acetate membranes was also tested. Membrane treatments reduced the regeneration of mature embryos from $55 \%$ in the control treatment to $45 \%$ when the membrane was applied during the first half of the 8-week maturation phase and to $25 \%$ when the membrane was applied during last four weeks of the maturation period. However, membrane treatments significantly enhanced the conversion of mature embryos to plants, increasing the embryo conversion rate from $1.5 \%$ in the control to an average value of $37.9 \%$ in the membrane treatment. Cotyledonary embryos that were matured on the membranes showed lower values of water and solute potential than controls, indicating that this treatment exerted a controlled desiccation rate that enhanced the recovery of plants.

Keywords In vitro plant regeneration $\cdot$ Olea europaea $\cdot$ Suspension culture $\cdot$ Semipermeable membrane $\cdot$ Somatic embryo $\cdot$ Water potential

\section{Abbreviations}

2iP 6-(Dimethylallylamino) purine

BA 6-Benzyladenine

DKW Driver and Kuniyuki medium

ECO Olive cyclic embryogenesis medium

IBA Inodole-3-butyric acid

MS Murashige and Skoog medium

OMc Olive medium

SE Somatic embryo

\section{Introduction}

Olive (Olea europaea L.) is an important crop in Mediterranean countries, although in the last few years, its cultivation has been extended throughout the world. Currently, the area of olive cultivation is approximately 9.7 million ha., with the European Union responsible for $75 \%$ of olive oil production, and Spain and Italy are the most important 
producer countries (FAOSTAT 2009). Today, most olive cultivars used commercially are the result of grower selection, and elite olive cultivars with outstanding agronomical traits derived from breeding programs are desirable. These programs, however, are time-consuming due to the long juvenile period of this species, which, despite being genotype dependent, generally lasts more than 10 years (Rugini and Baldoni 2005).

Olive is a difficult species to manipulate in vitro; however, its regeneration via somatic embryogenesis has generally been accomplished using different embryoderived explants, e.g., immature zygotic embryos (Rugini 1988; Maalej et al. 2002), cotyledons (Bhradda et al. 2003; Mitrakos et al. 1992), and radicles (Orinos and Mitrakos 1991) from mature embryos, as well as roots from germinated seedlings (Shibli et al. 2001). According to Rugini et al. (2005), the immature zygotic embryo is the most reliable explant since its response is not genotype-dependent. However, Mitrakos et al. (1992) have indicated that the radicle isolated from the mature embryo is also very responsive, and plant material can be available in the laboratory year-round. Although protocols for the induction of somatic embryos (SE) are available, the rate of conversion to healthy plants is rather low, making the application of somatic embryogenesis difficult for biotechnological purposes such as large-scale plant multiplication, cryopreservation or genetic transformation (Rugini et al. 2005).

The aim of this investigation was to develop an improved regeneration system for olive via somatic embryogenesis. Toward this end, several factors affecting the proliferation, maturation and germination of SE, such as basal formulation of culture medium, liquid medium pre-treatments or maturation on cellulose acetate semipermeable membranes, were evaluated.

\section{Materials and methods}

\section{Plant material, culture conditions and embryogenesis induction}

Mature olive (Olea europaea L., cv. Picual) seeds, stored for several months at $4^{\circ} \mathrm{C}$, were used. After elimination of the endocarp, seeds were sterilised with $70 \%$ ethanol for $1 \mathrm{~min}$ and later with $10 \%$ sodium hypochlorite for $20 \mathrm{~min}$. After the initial sterilisation, seeds were rinsed with sterile water for 5 min and kept floating in water for 48 hours in darkness. Afterwards, seeds were again sterilised with sodium hypochlorite solution of the same concentration indicated above, rinsed with sterile water and transferred to the laminar flow hood, where the radicle was dissected with care and used as an explant. 
The protocol used for SE induction was that recommended by Orinos and Mitrakos (1991), e.g., callus induction was achieved in OMc medium (Cañas and Benbadis 1988) supplemented with $2.5 \mu \mathrm{M} 2 \mathrm{iP}$ and $25 \mu \mathrm{M}$ IBA. After 3 weeks, explants were transferred to the same OMc medium without 2iP and a lower IBA concentration, 2.5 $\mu \mathrm{M}$, for development of embryogenic structures. Olive embryogenic calli were cultured in the dark at $25 \pm 2^{\circ} \mathrm{C}$ and subcultured onto fresh medium every 4 weeks. In germination experiments, cultures were grown under a $40 \mu \mathrm{mol} \mathrm{m}^{-2} \mathrm{~s}^{-1}$ irradiance level.

All media were adjusted to $\mathrm{pH} 5.74$ with $\mathrm{NaOH}$ or $\mathrm{HCI}(1 \mathrm{~N})$ before adding the solidifying agent, e.g., phytagel $3 \mathrm{~g} \mathrm{l}^{-1}$. Afterwards, media were autoclaved at $121^{\circ} \mathrm{C}$ and $0.1 \mathrm{MPa}$ for $20 \mathrm{~min}$ and distributed in $25 \mathrm{ml}$ aliquots in $25 \times 150 \mathrm{~mm}$ test tubes (BelIco Glass) or in Petri dishes. Test tubes were covered with kaputs (BelIco Glass, Inc.).

\section{Effect of basal formulation on embryogenic callus proliferation and embryo maturation}

To induce proliferation, SE and embryogenic masses were transferred to either the same basal medium used for culture initiation (OMc) or to ECO medium, a basal formulation with lower ionic strength than OMc. ECO medium was based on the OMe formulation (Cañas and Benbadis 1988) and contains 1/4 OM macroelements, 1/4 MS (Murashige and Skoog 1962) microelements, 1/2 OM vitamins, $50 \mathrm{mg} \mathrm{l}^{-1}$ myo-inositol, as well as an extra supplement of $550 \mathrm{mg}^{-1}$ glutamine (Cañas and Benbadis 1988). In both cases, basal media were supplemented with $1 \mathrm{~g} \mathrm{l}^{-1}$ casein hydrolysate, $0.5 \mu \mathrm{M} 2 \mathrm{iP}$, $0.44 \mu \mathrm{M}$ BA, $0.25 \mu \mathrm{M}$ IBA and $0.42 \mu \mathrm{M}$ cefotaxime, as recommended by Rugini and Caricato (1995), and solidified with $3 \mathrm{~g}^{-1}$ phytagel. Cefotaxime was filter-sterilised and added to the cooled medium after autoclaving. In this experiment, inoculum size was $300 \mathrm{mg}$. After 4 weeks, fresh weight increase and morphological traits such as texture, size of embryogenic structures and degree of friability were determined, and a new inoculum was taken for the subsequent subculture. Data were taken during 10 subcultures.

To induce maturation, isolated globular embryos were transferred to basal OMc or ECO media, e.g., without growth regulators and cefotaxime but supplemented with activated charcoal $1 \mathrm{~g} \mathrm{l}^{-1}$. Frequencies of mature SE regeneration, necrotic SE and callus formation, as well as embryo size, were recorded after the maturation phase. Twenty plates per maturation medium with 20 globular embryos per plate were used. Germination of mature SE took place in a modified MS medium with $1 / 3$ 
macroelements and $10 \mathrm{~g} \mathrm{l}^{-1}$ sucrose (Clavero-Ramírez and Pliego-Alfaro 1990). Regenerated plants were micropropagated and rooted in DKW medium (Revilla et al. 1996) and later acclimated to ex vitro conditions. Acclimated plants were grown in the greenhouse under natural conditions.

\section{Effect of pre-culturing in liquid medium on embryo maturation}

In this experiment, embryogenic masses of $400 \mathrm{mg}$ were cultured for 4 weeks on 100 $\mathrm{ml}$ of liquid ECO medium at $100 \mathrm{rpm}$. After filtering through a $3 \times 3 \mathrm{~mm}$ screen, globular embryos from the small fraction were transferred to maturation ECO medium for SE differentiation. In the control treatment, globular embryos were isolated from embryogenic calli proliferating in solid medium. Cotyledonary SE were then germinated in the medium of Clavero-Ramírez and Pliego-Alfaro (1990), and the percentage of embryos developing shoot, root, whole plants or calli after 12 weeks of culture was recorded.

\section{Effect of cellulose acetate membranes on embryo maturation}

Small, 1-3 mm, globular SE, obtained after filtering embryogenic masses grown for 4 weeks in liquid ECO medium through a $3 \times 3 \mathrm{~mm}$ mesh, were cultured on top of $4 \mathrm{x} 4 \mathrm{~cm}$ dialysis tubing cellulose acetate membranes (MW cut off 12000, Sigma D9777) in Petri dishes containing ECO maturation medium. Membranes were prepared following the manufacturer's instructions and autoclaved twice in distilled water at $121^{\circ} \mathrm{C}$ for $30 \mathrm{~min}$. Two different treatments were tested. In the M1 treatment, SE were cultured on the membranes during the firsts four weeks of the maturation phase and later transferred for 4 additional weeks to maturation medium without a membrane. In the M2 treatment, globular SE were first cultured in the maturation medium for 4 weeks without membranes and later cultured in the same medium over a cellulose acetate membrane for 4 additional weeks. The control treatment consisted of SE cultured for 8 weeks in maturation medium without a membrane. Frequencies of mature SE regeneration, necrotic SE and callus formation, and embryo size were recorded. Ten plates per treatment, with 20 globular embryos per plate, were used. Afterwards, 30 mature embryos at cotyledonary stage were germinated in $25 \times 150 \mathrm{~mm}$ test tubes, and formation of shoots and/or roots was evaluated. This experiment was repeated twice. 
Water potential $\left(\Psi_{\mathrm{w}}\right)$ in control and embryos matured on cellulose acetate membranes for 4 weeks, as described above for treatment M1, was measured by using a Wescor Dew Point Microvoltmeter HR-33T in the dew point mode. Isolated embryos were incubated in a C-52 sample chamber, and the dew point depression was recorded after 25 min of equilibration. Then, somatic embryos were frozen and thawed, and the dew point depression was measured again to determine the solute potential ( $\Psi$ s). Turgor pressure $(\Psi \mathrm{p})$ was estimated as the difference between $\Psi_{\mathrm{W}}$ and $\Psi_{\mathrm{s}}$. A minimum of 10 embryos per treatment were measured.

\section{Statistical analysis}

Data were subjected to analysis of variance using SPSS software. Tests for normality and homogeneity of variance were performed prior to ANOVA, and the Tukey or Dunn's tests were used for mean separation in case of homogeneous or nonhomogeneous variances, respectively. Frequency analyses were performed with the Gtest of independence, using BIOMstat software (Sokal and Rohlf 1995).

\section{Results}

\section{Somatic embryogenesis induction}

After 3 weeks of culture in the induction medium, radicles appeared swollen and of light green colour; friable calli were present in most explants. At this time, explants were transferred to a new medium with a lower IBA concentration of $2.5 \mu \mathrm{M}$. New roots could be observed in $35 \%$ of the explants after 6 weeks. Somatic embryos appeared after 9 weeks, and at 12 weeks, $25 \%$ of explants had formed these structures, which were isolated and transferred to proliferation media.

\section{Effect of basal medium on embryogenic callus growth and SE differentiation}

Radicle-derived embryogenic calli were cultured in two media with different ionic strengths, OMc or ECO. Throughout 10 subcultures, the average fresh weight increments obtained in the two proliferation media were not significantly different, showing an average value of $0.75 \pm 0.1 \mathrm{~g}$ per subculture. However, a large amount of SE cultured in OMc medium browned at the end of each subculture (Fig. 1a). Moreover, in this medium, globular structures disappeared if cultures were kept for more than 5 
weeks in the same medium, and calli became more compact and harder in texture. In contrast, embryogenic masses proliferating in ECO basal medium continued forming globular structures of light creamy colour (Fig. 1b).

For SE maturation, globular embryos growing in OMc or ECO medium were isolated and cultured in the same medium without growth regulators and supplemented with $1 \mathrm{~g} \mathrm{l}^{-1}$ activated charcoal. The percentage of explants giving rise to mature, cotyledonary-stage embryos after 8 weeks of culture was significantly higher in ECO than in OMc medium (Table 1). Furthermore, the number of mature SE developed from each initial globular embryo was also significantly higher when ECO medium was used (Table 1). Moreover, the maturation of olive embryos in ECO medium reduced the development of calli and the percentage of necrotic explants (Table 1). The appearance of the cultures after 8 weeks of maturation in OMc or ECO medium is shown in Fig. $1 \mathrm{c}$ and d, respectively. Therefore, based on these observations, ECO basal formulation was chosen for proliferation and maturation of the embryogenic masses. These cultures have been maintained for more than 4 years in this proliferation medium without observing changes in texture or loss of SE proliferation or differentiation capacity.

\section{Effect of pre-culturing on liquid medium on embryo maturation}

In this experiment, embryogenic callus was cultured in ECO liquid medium for 4 weeks and, after filtering through a $3 \times 3 \mathrm{~mm}$ screen, globular embryos from the small fraction were transferred to maturation medium. The pre-culture in liquid medium did not affect embryo maturation rate, and a similar regeneration percentage, 44\%, was obtained from globular embryos isolated from embryogenic calli maintained in solid media as those pre-cultured in liquid medium. However, pre-treatment in liquid medium increased the size of regenerated mature SE, with average lengths of $2.1 \pm 0.2$ vs. $3.0 \pm 0.4$ in control and liquid pre-treatments, respectively.

\section{Effect of cellulose acetate membrane on SE development}

To improve the regeneration of olive plants, the effect of culturing globular SE on cellulose acetate membranes during the maturation phase was evaluated. To this purpose, small globular SE pre-cultured in liquid medium were cultured in maturation ECO medium over cellulose acetate membranes for four weeks (Fig. 1e). This treatment was applied in the first half (4 weeks) of the eight-week maturation period (M1 treatment) or during the second half (last four weeks, M2 treatment). The regeneration 
of mature SE decreased when globular embryos were cultured on the membranes, especially in the M2 treatment (Table 2). The number of mature cotyledonary SE developed per globular embryo was also slightly lower in this treatment (Table 2). Membrane treatments also induced a higher percentage of callus formation and, when used during the last four weeks of the maturation phase, a higher proportion of dead explants (Table 2). Figure 1f-g shows the aspect of the SE after the M2 membrane treatment.

Mature SE were germinated in the medium of Clavero and Pliego-Alfaro (1990) and the percentages of SE developing shoot, root or whole plants were recorded after 12 weeks of culture. Shoot regeneration in control embryos was $12.5 \%$ (Fig. 2). However, the regeneration of roots and whole plantlets was low in this treatment, at $1.5 \%$. Conversely, $50 \%$ of control embryos formed calli after the 12 -week germination period. SE differentiated on the membranes yielded percentages of shoot or root formation significantly higher than those of the control treatment, and the regeneration of whole plants averaged $37.8 \%$ (Fig. 2). Figure 1h shows a 12-week-old germinated SE previously matured on the membrane. Notably, the percentage of root and whole plant regeneration was slightly higher when the membrane was applied during the last four weeks of maturation, M2 treatment, than in the first four weeks, M1 treatment. The development of calli in embryos that were matured on the membranes was also reduced (Fig. 2). Shoots developed from SE matured on the membrane showed higher proliferation rates than control shoots. Only $25 \pm 1 \%$ of shoots obtained from SE in the control treatment could be recovered and propagated in DKW medium; however, this percentage increased to $66.7 \pm 2.0 \%$ for shoots from SE matured on the membrane. After proliferation, shoots were rooted using the protocol of Revilla et al. (1996) and acclimated to ex vitro conditions, showing a phenotype similar to control plants (Fig. 1i).

To investigate the physiological basis of the beneficial effect of cellulose acetate membrane on SE development, water potential in control- and membrane-treated SE was measured at the end of the 8-week maturation phase. Cotyledonary embryos matured on the cellulose acetate membrane showed values of water and solute potential significantly lower than control embryos (Fig. 3). Turgor pressure, estimated as the difference between water and solute potential, was also significantly lower in the membrane-treated embryos when compared with control (Fig. 3). 


\section{Discussion}

Isolated radicles from mature seeds of the Spanish olive cv. Picual have shown an acceptable embryogenic capacity, with more than $25 \%$ of explants responsive to the protocol of Orinos and Mitrakos (1991). Salt requirements for somatic embryogenesis in olive seem to depend on the genotype used, e.g., Rugini (1988) recommended 1/2 MS medium to observe embryogenesis in immature zygotic embryo-derived calli of the Italian cultivars Dolce Agogia, Leccino, Frantoio and Moraiolo, and Orinos and Mitrakos (1991) also observed that a medium with reduced salt concentrations, half strength OMc (Cañas and Benbadis 1988), favoured the occurrence of somatic embryogenesis in radicle-derived calli of wild olives. In contrast, Brhadda et al. (2003), with calli derived from cotyledons of cv. Moroccan Picholine, found that the MS medium gave better results than other media with lower ionic strength, e.g., OMc, SH (Schenk and Hildebrand 1972) and BN (Bourgin and Nitsch 1967), with the poorest response being observed in OMc medium. Similarly, Capelo et al. (2010) observed higher rates of embryogenic callus induction in explants from mature wild olive cultured in MS medium than in those cultured in OM. This last medium, however, has been successfully used for cyclic proliferation of SE derived from cotyledon segments of cvs. Chetoui, Chemleli and Arbequina (Trabelsi et al. 2003). These conflicting results could reflect different nutritional requirements among genotypes. In our case, much better results were obtained with the ECO basal formulation, with low ionic strength, than with the OMc formulation. The ECO basal formulation is basically derived from that used by Cañas and Benbadis (1988) to induce olive root elongation, but this is the first time that a formulation with such a low ionic strength has been shown to have beneficial effects on olive somatic embryogenesis. The low content of mineral elements and vitamins could induce a stressful situation in culture favouring the proliferation of embryogenic cells; e.g., it has been shown that stress favours the initiation of the embryogenic process (Fehér et al. 2003; Quiroz-Figueroa et al. 2006).

Growing embryogenic cultures in suspension allows a better synchronisation of the cultures (Von Arnold 2008). However, prolonged culturing in liquid medium generally induces degeneration of cultures and a loss of embryogenic capacity (Litz et al. 2005; Von Arnold 2008) or increases the risk of the appearance of somaclonal variants (Etienne and Bertrand 2003; Von Arnold 2008). To our knowledge, somatic embryogenesis in suspension cultures has not yet been reported for olive, in spite of its benefit for the biotechnological improvement of this species (Mitrakos et al. 1992). 
Shibli et al. (2001) successfully established cell suspensions from radicle-derived calli of Nabali cultivar, but cell cultures did not undergo embryogenesis. In this study, we show that the culture of olive calli in liquid medium for 4 weeks followed by sieving through a $3 \times 3 \mathrm{~mm}$ mesh did not affect the recovery of mature somatic embryos and even increases the size of mature embryos. The superior behaviour of embryogenic suspensions is important for the genetic transformation of this species because embryogenic masses cultured in solid medium showed a high tolerance to the antibiotic used for selecting transgenic lines (Pérez-Barranco et al. 2009; Torreblanca et al. 2010).

Studies on SE maturation and germination in olive are scarce, even though the low conversion rate is one of the major bottlenecks in olive somatic embryogenesis (Rugini et al. 2005). Abscisic acid has been used to synchronise embryo maturation, but other treatments, e.g., chilling and growth regulator inhibitors, have been ineffective (Rugini and Baldoni 2005). A common procedure for the maturation of high quality SE is the culture of embryogenic tissues in media with decrease osmotic water potential by increasing the concentration of sucrose, gelling agents or by supplementing nonplasmolysing osmoticum (Krajňáková et al. 2009; Troch et al. 2009). In this investigation, we explored an alternative approach, the use of cellulose acetate semipermeable membranes for embryo maturation. This treatment has been successfully used by Niedz et al. (2002) for normalising the development of citrus SE. The culture of small olive globular embryos on the membrane reduced the number of regenerated mature cotyledonary embryos; however, membrane-matured embryos are of superior quality than those cultured directly on solid medium, as reflected by the significant increase in the percentage of plantlets recovered after germination. The mechanisms underlying the beneficial effect of cellulose acetate membranes in embryo maturation are unclear. During maturation, embryos undergo morphological and biochemical changes involving the deposition of storage proteins, repression of germination and acquisition of desiccation tolerance (Braybrook and Harada 2008). Niedz et al. (2002) found that water availability was substantially modified when culturing citrus embryos on a semi-permeable membrane. However, this water limitation was not replicated by increasing gel concentration or by the addition of PEG to the culture medium, since these treatments did not improve embryo development. The maturation of oak SE in media with increased agar concentrations reduced water availability and solute potential of SE, improving their germination rate (Prewein et al. 2004). In our study, we have also found that membrane treatments reduced embryo water potential and increased 
solute accumulation, reflected as a lower solute potential. It is thought that desiccation improves the germination frequency of $\mathrm{SE}$, either by reducing endogenous $\mathrm{ABA}$ content or by changing the sensitivity to ABA (Prewein et al. 2004; Jiménez 2005). Finkelstein et al. (1985), however, hypothesised that maturation of rapeseed embryos relies on low water content or some factor other than ABA. A deeper study of the metabolic changes induced by the culture of SE on the cellulose acetate membrane would be necessary to understand its role on olive SE maturation, but it is conceivable that the controlled desiccation exerted by the membrane resembles more closely the natural changes observed in zygotic embryos.

In conclusion, we have developed an efficient regeneration protocol via somatic embryogenesis for juvenile olive explants. Main features of this protocol are the maintenance of embryogenic cultures in a low ionic strength mineral formulation, the use of liquid medium for synchronisation and selection of the small embryo fraction, and the maturation of SE on semi-permeable cellulose acetate membranes for four weeks. These improvements in the regeneration protocol are currently being used for the genetic transformation of this species.

\section{Acknowledgements}

This research was funded by Dirección General de Investigación y Formación Agraria y Pesquera, Consejería de Agricultura y Pesca, Junta de Andalucía (Project CAO00-018C7-5) and Agencia Española de Cooperación Internacional para el Desarrollo (Project A/017856/08).

\section{References}

Bhradda N, Abousalim A, Walali LDE (2003) Effects du milieu de culture et de la lumière sur l'embryogenèse somatique de l'olivier (Olea europaea L.) cv. Picholine marocaine. Fruits 58:167-174

Bourgin JP, Nitsch JP (1967) Obtention de Nicotiana haploïdes a partir d'étamines cultivées in vitro. Ann Physiol Veg 9:377-382.

Braybrook SA, Harada JJ (2008) LECs go crazy in embryo development. Trends Plant Sci 13:624-630

Cañas LA, Benbadis A (1988). In vitro plant regeneration from cotyledon fragments of the olive tree (Olea europaea L.). Plant Sci 54:65-74 
Capelo AM, Silva S, Brito G, Santos C (2010) Somatic embryogenesis induction in leaves and petioles of a mature wild olive. Plant Cell Tiss Organ Cult 103:237-242 Clavero-Ramírez I, Pliego-Alfaro F (1990) Germinación in vitro de embriones maduros de olivo (Olea europaea ). Actas de Horticultura 1:512-516

Etienne H, Bertrand B (2003) Somaclonal variation in Coffea arabica: effects of genotype and embryogenic cell suspension age on frequency and phenotype of variants. Tree Physiol 23:419-426

FAOSTAT (2009) http://faostat.fao.org/

Fehér A, Pasternak TP, Dudits D (2003) Transition of somatic plant cells to an embryogenic state. Plant Cell Tiss Organ Cult 74:201-228

Finkelstein RR, Tenbarge KM, Shumway JE, Crouch ML (1985) Role of ABA in maturation of rapeseed embryos. Plant Physiol 78:630-636

Jiménez VM (2005) Involvement of plant hormones and plant growth regulators on in vitro somatic embryogenesis. Plant Growth Regulat 47:91-110

Krajňáková J, Häggman H, Gömöry D (2009) Effect of sucrose concentration, polyethylene glycol and activated charcoal on maturation and regeneration of Abies cephalonica somatic embryos. Plant Cell Tiss Organ Cult 96:251-262

Litz RE, Witjaksono, Raharjo S, Efendi D, Pliego-Alfaro F, Barceló-Muñoz A (2005) Persea americana avocado. In: Litz RE (ed.) Biotechnology of Fruit and Nut Crops. CABI Publishing, Wallingford, Oxfordshire pp. 326-347

Maalej M, Drira N, Chaari-Rkhis A, Trigui A (2002) Preliminary results of somatic embryogenesis from young zygotic embryos of olive tree. Acta Hort 586:899-902

Mitrakos K, Alexaki A, Papadimitriou P (1992) Dependence of olive morphogenesis on callus origin and age. J Plant Physiol 139:269-273

Murashige T, Skoog F (1962) A revised medium for rapid growth and bioassays with tobacco tissue cultures. Physiol Plant 15:473-497

Niedz RP, Hyndman SE, Wynn ET, Bausher MG (2002) Normalizing sweet orange ( $C$. sinensis (L.) Osbeck ) somatic embryogenesis with semi-permeable membranes. In Vitro Cell Dev Biol Plant 38:552-557

Orinos Th, Mitrakos K (1991). Rhizogenesis and somatic embryogenesis in calli from wild olive (Olea europaea var. sylvestris (Miller) Lehr) mature zygotic embryos. Plant Cell Tiss Organ Cult 17:183-187

Pérez-Barranco G, Torreblanca R, Padilla IMG, Sánchez-Romero C, Pliego-Alfaro F, Mercado JA (2009) Studies on genetic transformation of olive (Olea europaea L.) 
somatic embryos: I. Evaluation of different aminoglycoside antibiotics for $n p t I I$ selection. II. Transient transformation via particle bombardment. Plant Cell Tiss Organ Cult 97:243-251

Prewein C, Vagner M, Wilhelm E (2004) Changes in water status and proline and abscisic acid concentrations in developing somatic embryos of pedunculate oak (Quercus robur) during maturation and germination. Tree Physiol 24:1251-1257

Quiroz-Figueroa FR, Rojas-Herrera R, Galaz-Avalos RM, Loyola-Vargas VM (2006) Embryo production through somatic embryogenesis can be used to study cell differentiation in plants. Plant Cell Tiss Organ Cult 86:285-301

Rugini E (1988) Somatic embryogenesis and plant regeneration in olive (Olea europaea L.). Plant Cell Tiss Organ Cult 14:207-214

Rugini E, Caricato G (1995) Somatic embryogenesis and plant recovery from mature tissues of olive cultivars (Olea europaea L.) 'Canino' and 'Moraiolo'. Plant Cell Rep 14:257-260

Rugini E, Baldoni L (2005) Olea europaea Olive. In: Litz RE (ed) Biotechnology of Fruit and Nut Crops. CABI Publishing, Wallingford, Oxfordshire, pp 404-428

Revilla MA, Pacheco J, Casares A, Rodríguez R (1996) In vitro reinvigoration of mature olive trees (Olea europaea L.) through micrografting. In Vitro Cell Dev Biol Plant 32:257-261

Rugini E, Mencuccini M, Biasi R, Altamura MM (2005) Olive (Olea europea L.). In Jain SM, Gupta PK (eds) Protocol for Somatic Embryogenesis in Woody Plants. Springer, Dordrecht, pp 345-360

Schenk RU, Hildebrand AC (1972) Medium and technique for induction and growth of monocotyledoneous and dicotyledoneous plant cell cultures. Can J Bot 50:199-204

Shibli RA, Shatnawi M, Abu-Ein, Al-Juboory KH (2001) Somatic embryogenesis and plant recovery from callus of 'Nabali' olive (Olea europaea L.). Sci Hortic 88:243256

Sokal RR, Rohlf FJ (1995) Biometry. W. H. Freeman and Company, New York

Torreblanca R, Cerezo S, Palomo-Ríos E, Mercado JA, Pliego-Alfaro F (2010) Development of a high throughput system for genetic transformation of olive (Olea europaea L.) plants. Plant Cell Tiss Organ Cult 103:61-69

Trabelsi EB, Bouzid S, Bouzid M, Elloumi N, Belfeleh Z, Benabdallah A, Ghezel R (2003) In-vitro regeneration of olive tree by somatic embryogenesis. J Plant Biol 46:173-180 
Troch V, Werbrouck S, Geelen D, Van Labeke M-C (2009) Optimization of horse chestnut (Aesculus hippocastanum L.) somatic embryo conversion. Plant Cell Tiss Organ Cult 98:115-123

Von Arnold S (2008) Somatic embryogenesis. In: George EF, Hall MA, De Klerk G-J (eds.) Plant Propagation by Tissue Culture 3rd edition. Vol. 1. The Background. Springer, Dordrecht, pp 335-354 
Table 1: Effect of basal medium on maturation of olive SE. Explants, globular embryos, were matured for 8 weeks on OMc or ECO basal formulations without growth regulators and supplemented with $1 \mathrm{~g} \mathrm{l}^{-1}$ activated charcoal.

\begin{tabular}{lcc}
\hline & OMc medium & ECO medium \\
\hline Explants regenerating mature SE (\%) & $25.7 \pm 10.0 \mathrm{~b}$ & $48.7 \pm 11.4 \mathrm{a}$ \\
Number of mature SE per explant & $1.7 \pm 0.5 \mathrm{~b}$ & $2.2 \pm 0.7 \mathrm{a}$ \\
Explants forming callus (\%) & $60.0 \pm 13.3 \mathrm{a}$ & $47.0 \pm 10.3 \mathrm{~b}$ \\
Necrotic explants (\%) & $14.3 \pm 8.6 \mathrm{a}$ & $4.3 \pm 4.1 \mathrm{~b}$ \\
\hline
\end{tabular}

*Mean separation was performed by Tukey test in the case of the number of mature SE or G-test of independence at $\mathrm{P}=0.05$. 
Table 2: Effect of cellulose acetate membranes in the maturation of olive SE. Explants, globular embryos, were matured for 8 weeks on maturation ECO medium without membrane (control) or on cellulose acetate membranes during the first half of the 8week maturation phase (M1 treatment) or the second half (M2 treatment).

\begin{tabular}{lccc}
\hline & Control & M1 & M2 \\
\hline Explants regenerating mature SE (\%) & $56.5 \pm 13.3 \mathrm{a}$ & $40.6 \pm 10.2 \mathrm{~b}$ & $18 \pm 8.2 \mathrm{c}$ \\
Number of mature SE per explant & $1.7 \pm 0.2 \mathrm{a}$ & $1.8 \pm 0.4 \mathrm{a}$ & $1.2 \pm 0.2 \mathrm{~b}$ \\
Explants forming callus (\%) & $39.0 \pm 13.5 \mathrm{~b}$ & $53.1 \pm 11.6 \mathrm{a}$ & $55.5 \pm 0.6 \mathrm{a}$ \\
Necrotic explants (\%) & $5.5 \pm 3.6 \mathrm{~b}$ & $6.2 \pm 3.5 \mathrm{~b}$ & $26.5 \pm 12.0 \mathrm{a}$ \\
\hline
\end{tabular}

* Mean separation was performed by Tukey test in the case of the number of mature SE or G-test of independence at $\mathrm{P}=0.05$. 
Figure legends

Figure 1: a-b: Appearance of embryogenic calli after 4 weeks of culture in OMc (a) or ECO (b) proliferation media. c-d: Maturation of SE in OMc (c) or ECO (d) maturation media. Pictures were taken at the end of the 8-week maturation phase. e: globular SE cultured on the cellulose acetate membrane for differentiation. f: Aspect of cultures after the four-week cellulose acetate membrane treatment (M2 treatment). g: Mature cotyledonary SE matured on cellulose acetate membrane (M2 treatment). Pictures $f$ and $\mathrm{g}$ were taken at the end of the 8-week maturation phase. h: Twelve-week-old germinated SE previously matured on the membrane (M2 treatment). i: Acclimated plant derived from an SE matured on the membrane. In all figures, bars correspond to $5 \mathrm{~mm}$.

Figure 2: Germination frequencies of SE matured without (control) or with cellulose acetate membrane (M1 and M2). M1: SE cultured on the membrane during the first 4 weeks of the maturation phase. M2: SE cultured on the membrane during the last 4 weeks of the maturation phase. Data correspond to the mean $\pm \mathrm{SE}$ of embryos forming shoot, root, plantlet (shoot + root) or callus. Frequencies were analysed with G-test of independence at $\mathrm{P}=0.05$.

Figure 3: Water potential $(\Psi \mathrm{w})$, solute potential $(\Psi \mathrm{s})$ and turgor pressure $(\Psi \mathrm{p})$ of cotyledonary SE matured without (control) or with cellulose acetate membrane during the first half ( 4 weeks) of the maturation period. Data were recorded at the end of the 8 week maturation phase and correspond to mean \pm SD. Mean separation was performed by Dunn test in the case of $\Psi_{\mathrm{w}}$ and $\Psi \mathrm{p}$, or Tukey test $(\Psi \mathrm{s})$ at $\mathrm{P}=0.05$. 

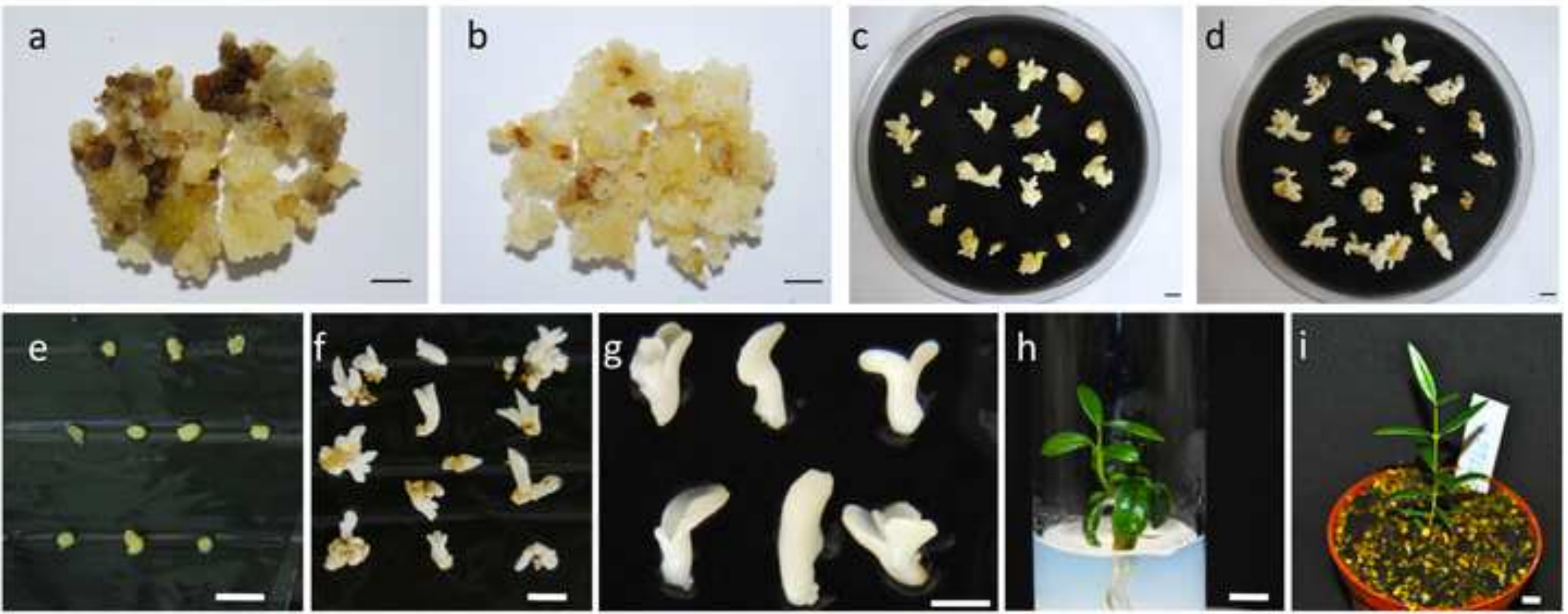
Figure 2

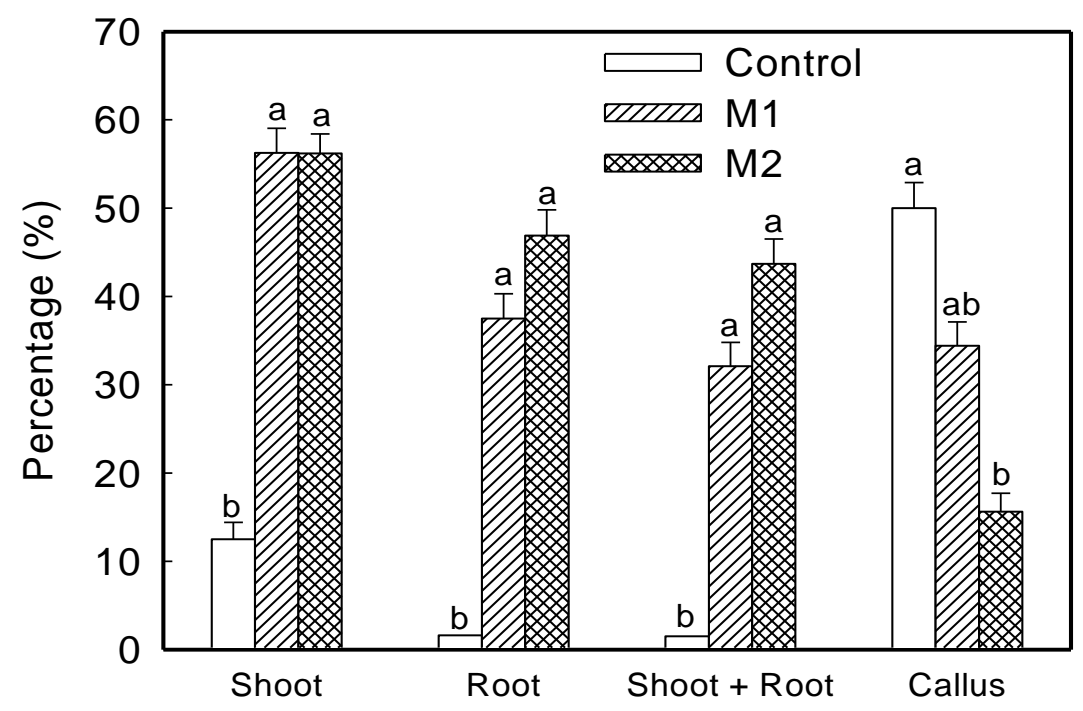


Figure 3

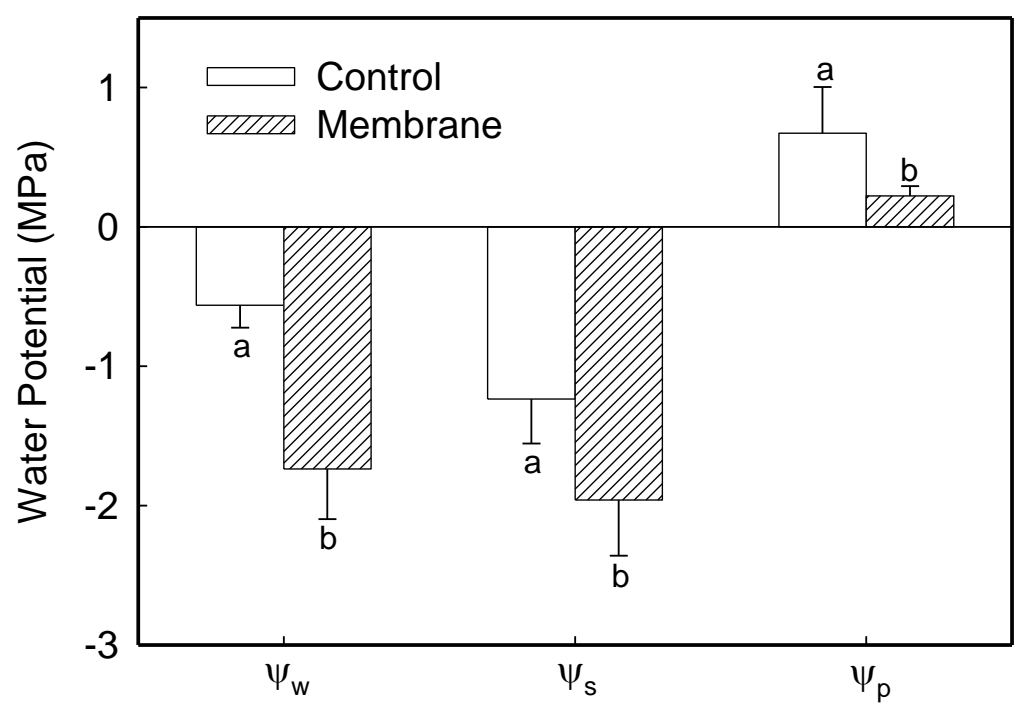

